\title{
Feasibility of College Japanese Major and Japanese Joint Training Projects
}

\author{
Zou Wei
}

Xi'an University, Xi'an, 710065

\begin{abstract}
In $\quad$ recent Education and the Japanese Ministry of years, university exchanges between China and Japan is more active, we can see that in the joint efforts of China and Japan, the scale of cooperation is expanding, understanding and friendship between the young people are gradually deepened. The long-term stability of University conducted exchanges and cooperation in education with Japan is the concrete manifestation of China's opening-up. Therefore, what's the meaning of joint training of undergraduate education in universities? This paper studies on " $2+2$ " program between our college and the west of the international University of Japan. We analysis the favorable and unfavorable factors in joint University, Fudan University, Shanghai Jiaotong University signed joint training program respectively with Kyoto University, Osaka University and other colleges or universities of Tokyo in Japan, In 2009, the Japan universities had set up 97 offices in China, which was far exceeded than in the United States, South Korea and other countries.

Sino-Japanese joint training has now become a common form of communication and cooperation between Chinese and Japanese universities, then, we will detailed analyzed whether they have favorable and unfavorable factors in the joint training projects.
\end{abstract} training programs, clarify the necessity and feasibility of acting joint training programs, and provide some reference for the development of our joint training program.

Keywords- Undergraduate education, Co-culture, Favorable factors, Feasibility, Teaching model

\section{INTRODUCTION}

Joint training is a new educational concepts and models, which simply means the education mode between or among different cultures. In this mode, your education is multifaceted; knowledge is broader, which is to meet the requirement of social compound talents. In recent years, university exchanges between China and Japan is more active. According to the survey from the Chinese Ministry of

2. Research on the subject of the joint training project study

Gen Yiqun (2005) analyzes in "Degrees and Graduate Education" about the postgraduate education internationalization situation and policy in various countries. Li Gang, Tian Xueyi (2009) discusses the graduate education in the international development problems and solutions in "Heilongjiang education"; Luo Yaocheng (2009) in "Graduate Education" talks about the internationalization of our graduate education and universities, and carries out a detailed analysis of the status and puts forward some suggestions. Zhao Wei (2003), in "Degrees and Graduate Education," clarifies on 
promoting the internationalization of our graduate education.

In this paper, we specialize in Japanese major of the joint training programs on undergraduate feasibility analysis, and seek to provide a reference for our future Japanese undergraduate education

\section{Background of carrying out joint training project of Japanese major education}

\subsection{International background}

First, economic globalization leads to the flow of globalization of higher education resources. With the advent of economic globalization, higher education will gradually implement market-oriented, has become unavoidable, which inevitably requires a variety of educational resources flow in the world market to achieve optimal allocation of educational resources. This trend has been noted by many countries of the world, especially the developed countries have to take full advantage of this feature, who can use a variety of international education and resource utilization we need to develop their own talent and seize global market share.

For this trend of many colleges and universities also give a positive response, through educational exchanges and cooperation of Chinese and foreign colleges and universities, many colleges and universities improved the visibility and competitiveness in a relatively short period of time, not only to the society a large number of high-quality talent, but also to draw foreign high-level university education experiences in the shortest time, and gradually reduce the gap between the level of foreign education.

\section{2 Domestic Background}

The State encourages Chinese higher education institutions and foreign well-known institutions of higher education to do cooperative education, encourage foreign cooperative education institutions to introduce advanced courses and teaching materials in the international arena, especially in conjunction with China's reality. We should pay attention to learn from foreign educational institutions management experience and successful school characteristics, so that our educational institutions will have a comparative advantage. Increasingly education policy open for cooperation and exchange of Chinese and foreign colleges and universities to provide a guarantee political.

\section{The status of development of the Japanese joint training program in college and universities}

4.1. Beijing Language and Culture University and Hokuriku University conducted joint training Japanese and Law double bachelor degree program. First and second grade at Beijing Language and Culture University to mainly study Japanese language courses and minor in English, computer, legal and professional foundation courses and some public course. After the end of two years of study, participate in a unified Hokuriku University incorporated exam, who can participate in the project by entering the Hokuriku University and according to the teaching program Hokuriku University learning. Two schools provide the required credits to complete graduation papers are to graduate, get two school diploma and degree certificates.

4.2. Guangdong University of Foreign Studies International University launched a joint international training project respectively with, 
Nagasaki Wesleyan University, Hokkaido Bunkyo University, Japan Hokuriku University in Japan.

4.3. Hebei University Japanese major and Japanese Suzuka International University launched the "2 + 2" interdisciplinary cooperative education program.

In addition, according to the Chinese Ministry of Education and the Japanese Ministry of Education related to the survey, China's Tsinghua University, Peking University, Fudan University, Shanghai Jiaotong University, Wuhan University, Tongji University, Xi'an Jiaotong University, Xi'an International Studies University, respectively signed a joint training project with many universities of Tokyo University, Kyoto University, Osaka University, Waseda University, Keio University, Hokkaido University, Hiroshima University, Nagoya University.

\section{Favorable and unfavorable factors of Sino-Japanese Joint training project}

\subsection{Favorable factors:}

5.1.1 Chinese and Japanese peoples have a long history of exchange history, influence each other culturally and geographically.

5.1.2 Compared with European and American countries, Japan implemented excellent tuition waiver system for students.

\subsection{Unfavorable factors:}

5.2.1 Structural contradictions between the two countries. Geopolitical conflicts, relations between big powers, economic interests caused by the impact of deep-seated reasons of bilateral cooperation.

5.2.2 Universities in Western China subject to geographical restrictions, outreach efforts should be strengthened, not only to actively "invite in", but also take the initiative to "go out."

5.2.3 There are differences, such as subject classification, research methods between Chinese and Japanese education system.

5.2.4 Further discussion need to be conducted to explore student management of joint training.

\section{Significance of undertaking college Japanese major joint training projects}

6.1 Since geographical constraints of Chinese Western Universities, Our College Japanese Professional \& Universities of Japan joint training project has just started, this project will help our college outreach link closely with economic development of cultural industries in $\mathrm{Xi}$ 'an, reflecting the economic and cultural development in Xi'an characteristics of the times.

6.2 The subject helps to promote the teaching content reform to establish joint training projects, which can give timely feedback whether the Japanese professional training model is reasonable and thus adjust and update teaching content.

6.3 In the process of joint training, students can take advantage of both the school and mentor in the study of many different strengths perspective, methods, teaching resources, research environment and academic exchange platform, to expand the horizons of scientific research, research capacity and research to improve the standards.

6.4 Research on the subject will help to carry out international academic exchange in foreign learning and experience, so that students can get a full international exchanges opportunity to participate in various academic exchange activities, to develop their overall academic ability. 


\section{Necessity of conducting joint training projects of Japanese major}

Conduct joint training of undergraduate and Japan is a new attempt to build talent training mode reform, not only help to improve the overall quality of students, and can effectively promote exchanges between Chinese and Japanese Universities and cooperation in various fields, there are conducive to high-quality resources sharing, complementary advantages and achieve common development. Secondly, since the Japanese professional particularity, many students did not appear before the university contacted the Japanese, can be said to beginners, so the domestic Japanese undergraduate education or to stay on the main level of the main teachers teach, students learn many Japanese are just able to pass examinations only. So we are opposed to this practice of teaching, which is actually not meet the requirements of personnel training.

\section{The exploration of curriculum model in Japanese major in joint training project}

8.1 Increase professional content in Japanese textbooks in the original textbooks, which can directly use the textbooks in Japan, or to increase similar content textbooks in Japan. Or to specify a considerable number of foreign materials and related foreign essays as a teaching bibliography.

8.2 Set up a special international education programs in public basic courses and cultural diathesis in order to make students understand the way of thinking, habit and others of people in other countries.

8.3 Introduce the frontier discipline to narrow the gap with the developed countries of the current disciplines. There is a considerable gap between us and developed countries especially in the natural sciences and economic fields. As Chen Zhangwu, professor at Tsinghua University said "Textbook of Colleges and Universities are quite old in a considerable part, there are many deficiencies in teaching content, curriculum, etc., and it is difficult to cultivate a competitive international talent."

\section{Conclusions}

Chinese universities shall cooperate in personnel training process with attention in the natural sciences and high-tech field, using the latest version of the original materials, improving our fall discipline and course structure and teaching content with foreign advanced ones.

\section{Acknowledgement}

This research was financially supported by the Xi'an Social Science Foundation of Year 2015 (Grant NO. 15WL07)

\section{References}

[1] Geng Yiqun, The Current Situation of the Internationalization of Graduate Education in Some Western Countries and the Policy Analysis, Academic Degrees \& Graduate Education, 2005.

[2] Li Gang and Tian Xueyi, Problems and Strategies in the International Development of Postgraduates Education, Heilongjiang Education, 2009

[3] Luo Yaocheng, Internationalization of Graduate Education in China, Academic Degrees \& Graduate Education, 2009.

[4] Wang Genshun and Wanghui, Initiation and practice of cultivating internationalized talents in research universities in China, 
Journal of National Academy of Education Administration, 2009.

[5] Zhao Wei, Thoughts on Promoting the
Globalization of Chinese Graduate Education, Academic Degrees \& Graduate Education, 2003. 